\title{
Digital humanities: prospects for knowledge transfer
}

\author{
Ivan Aladyshkin \\ Higher School of Social Sciences \\ Peter the Great St.Petersburg \\ Polytechnic University \\ St. Petersburg, Russia \\ i-bez@yandex.ru \\ Svetlana Ulyanova \\ Higher School of Social Sciences \\ Peter the Great St.Petersburg \\ Polytechnic University \\ St. Petersburg, Russia \\ oulianova@mail.spbstu.ru
}

\author{
Natalya Anosova \\ Department of Linguistics and \\ intercultural communication \\ Peter the Great St.Petersburg \\ Polytechnic University \\ St. Petersburg, Russia \\ natalia-ed@mail.ru
}

\author{
Sergey Kulik \\ Higher School of Social Sciences \\ Peter the Great St.Petersburg \\ Polytechnic University \\ St. Petersburg, Russia \\ kulik54@mail.ru
}

\begin{abstract}
The paper discusses the problems of knowledge transfer in the field of digital humanities (Digital humanities/DH). The transformation of ideas about digital humanities reflected in the latest publications is critically reviewed and the proposal to include relevant educational practices in this concept is grounded. The authors have made the forecast of digital humanities development based on the prospects of the 4th Industrial Revolution that radically change the relationship between the market and scientific environment. The paper presents the analysis of the factors that determine the importance of knowledge transfer in the humanities and the role of $\mathrm{DH}$ in the commercialization of intellectual potential. The authors suggest a new vision of knowledge transfer, pay special attention to the difficulties in its development in the Russian digital humanities and highlight promising areas of knowledge transfer programs for $\mathrm{DH}$. The conclusion is made that it is necessary to update the knowledge transfer in the field of digital humanities re-focusing the research and development in this field.
\end{abstract}

Keywords - digital humanities, knowledge transfer, e-culture, digital revolution, knowledge economy

\section{INTRODUCTION}

The fourth industrial revolution (industry 4.0) is increasingly taking on the features of reality, transforming all spheres of life in modern society. Science and education are also moving towards the development of knowledge economy. Its key components are based on rapidly increasing digitalization, which predetermines the change in the key areas of scientific knowledge. The humanities are no exception, and digital humanities (DH) are becoming a sought-after version of knowledge about man and society.

Keeping the focus on commercialization and the international integration of science and education, the knowledge economy focuses on their economic implementation. In this context, the problem of the transfer of knowledge, which plays an important role in current models of the scientific and educational environment, is considered in digital humanities.

The concept of "knowledge transfer" closely related to the term "technology transfer" is discussed in many foreign and Russian studies [1, 2, 3, 4]. In terms of the knowledge transfer study, J. Salmi, D. Siegel, A. Link, D. Movery, B.
Sampat et al. pointed out the high relevance of the transformation of higher education in the conditions of intensified globalization $[5,6,7]$.

The relevance of this research area is also confirmed by the conferences dedicated to specific models of knowledge transfer between the Russian and other national educational systems ("Transfer of knowledge in science, education and business: ways of interaction between Russia and Germany", Arkhangelsk, October 15-19, 2014).

Terminological discussion regarding the transfer of knowledge is still ongoing. This term is gradually replacing the earlier concept of "technology transfer" [4]. Some experts are discussing the «exchange of knowledge» between scientific and educational institutions, businesses, governmental and public bodies [8]. The change of concepts reflects the desire for the broad understanding of the intellectual potential of the scientific community. As a result, today knowledge transfer is understood as organizational systems and processes through which knowledge, including technology, experience and skills, is transferred from one side to another, thus bringing innovations in the economy and social sphere [9].

Today, in the framework of knowledge transfer, along with the usual practice of contract research and licensing, other forms of commercialization of research results and educational practices are considered. The implementation of market-oriented educational programs that involve a certain economic effect for the customer can be given as an example of such projects. The so-called "light" forms of knowledge transfer include the organization of conferences, the creation of electronic networks, etc.

In the face of cuts in public funding, the need to provide alternative sources of investment and competitiveness in the market for research and educational services, there are great expectations for knowledge transfer. However, considering the forms and mechanisms of knowledge transfer, the researchers are mainly focused on high technology industries neglecting the areas of humanities. In our opinion, this is due to underestimation of the extent of humanities digitization and its possibilities. follow. 


\section{MATERIALS AND MethodS}

The "Manifest for the Digital Humanities" published in 2010 by M.Dakos, Professor of History, Director of the French Center for open electronic publishing, proclaimed: "The digital humanities designate a "transdiscipline", embodying all the methods, systems and heuristic perspectives linked to the digital within the fields of humanities and the social sciences" [10].

The convergence of humanitarian knowledge and digital technologies had been outlined long before the concept of digital humanities emerged. Beginning from the 1960s 1970s, individual humanities (linguistics, history, archeology) used computer technology quite successfully [11]. In the late 1980s and especially in the 1990s, due to the rapid development of computer visualization tools and network technologies, the digitalization of the entire spectrum of the humanities accelerated noticeably. Digital Humanities were developed in leading universities in the USA, Canada, Australia, Holland, Great Britain, etc.

In the mid-2000s there was a definite historiographic "transition" associated with the advent of this area of scientific research [12]. Before this transition various projects in the field of Humanities Computing had developed relatively autonomously, while the new millennium saw the processes of virtual globalization of humanitarian research infrastructures and the development of the common digital space Digital Humanities (eHumanities). So, we can conclude that the digital turn took place, within which researchers shifted from the "technical support" of traditional linguistic, historical, anthropological and other types of research to a new methodology. For some time, digital humanities were presented as an intellectual breakthrough with qualitatively different professional practices, scientific standards and theoretical constructs [13].

In the modern world, humanitarian knowledge and technology are effectively combined, and it is no longer possible to develop the humanities, ignoring the role of information technology [14].

At the same time, the apology of information and communication technologies often turns into the fact that digital humanities are reduced to software that allows you to expand the capabilities of research in humanities through the use of computer programming and modeling tools, databases, information retrieval algorithms, graphical visualizations, etc [15]. Reducing digital humanities to technical parameters is not entirely justified, although their success and relevance are largely due to the development of networking and multimedia technologies (on the example of historical science [16]). The latter also determined a gradual shift in research practice from measuring to reconstruction and presentation capabilities of computer technologies [17, 18]. Most researchers agree on the fact that digital historical and cultural heritage should be expanded through the publication in electronic resources, reconstruc-tion and visualization.

Today, almost all kinds of scientific research are initiated, stored and distributed using computer and telecommunication technologies. An increasing proportion of the cultural heritage is being digitized, and it takes on elements of augmented reality and acquires a new life in the virtual space. A significant part of the scientific space is "born digital", and is stored digitally. Therefore, simply using the methods of computer processing of research materials or transferring its results to the virtual environment is not enough to highlight the scientific field of $\mathrm{DH}$.

Researchers agree on the fact that digital humanities are a project-based ap-proach to solving scientific problems, resulting not only in scientific text, but also in a certain information digital product [19]. The widely acclaimed project of Moscow historians "Virtual Reconstruction of Moscow Holy Monastery (mid XVII - early XX centuries): the analysis of spatial infrastructure evolution based on 3D modeling methods" can be given as one of the examples, as well as the University of Southampton project "Mapping Medieval Chester" (C. Clarke) and the project "Digital History of the St. Petersburg Polytechnic University" [20, 21, 22].

\section{RESULTS}

Today, the area of digital humanities is a dynamic field of scientific activity, both worldwide and in Russia. More than ten DH research and educational centers (Moscow State University named after M.V. Lomonosov; Perm State University; Tomsk State University; Higher School of Economics, etc.) are working in the Russian "digital humanities environment". Various thematic conferences are organized in this field and issues of specialized journals (Informational Bulletin of the Association "History and Computer", Historical Informatics, Humanitarian Informatics, etc.) are released. With regard to Russian researchers, the statement of $\mathrm{W}$. Thomas is quite up-to-date: "Historians, literary critics, philosophers, philologists, scientists who have discovered the digital humanities, are beginning to restructure scientific activity and its organizational forms for the new digital world. Scientists have become open to a wide variety of research methods, to exchange sources and materials (data), and have recognized large-scale distributed models of research projects" [23].

In the concepts of digital humanities, it is important to mention that their focusing exclusively on research practices significantly narrows the area under consideration. Meanwhile, the concept of "digital humanities" should also include educational practices, since many digital projects in the social sciences and humanities are focused on solving scientific, educational and educational tasks simultaneously [11].

Today there is a wide use of e-learning systems, introduction of information and educational environments in higher education, development of curricula directly related to digital humanities (for example, the Bachelor of Intellectual Systems in the Humanities, Federal Educational Standard 45.03.04). This makes the problem of knowledge transfer in the context of DH development quite relevant.

The digitization of the main areas of the scientific and educational space is inevitable in the light of the knowledge economy adopted in Russia [24]. Digital humanities appear to be most appropriate to the new format of key social areas predetermined by industry 4.0 (mass implementation of biological systems in production, automation of most production processes, artificial intelligence and total 
digitization) [25]. In fact, we can talk about humanitarian support of scientific and technological projects developed in other industries (public history, digital archives, technologisation of discourse, etc).

The digital component gives the humanities additional opportunities for the commercialization of intellectual potential. That is why all models of science and education renovation pay special attention to the transfer of knowledge, which ensures effective interaction between education, research and innovation in the digital age. However, this problem still lacks adequate theoretical background.

In the case of academic transfer of knowledge, the main actors are the scientific community and customers, both external (enterprises, public and state bodies), and internal (scientific and educational institutions).

The effective knowledge transfer in the humanities in Russia is hampered by the tradition of considering the transfer of knowledge exclusively in the context of nature and technical sciences, skepticism regarding the possibility of commercializing the results of humanitarian research, exclusion of humanities issues from the main areas of state science and technology policy, and also "disciplinary decadence" (L. Gordon's term) that resulted in the loss of connection between the disciplines and reality [26].

Meanwhile, the analysis of foreign experience shows that economically developed states demonstrate a great interest in the development of a digital ecosystem of humanitarian knowledge. The relevance of scientific information about the nature of society and the state in the context of global transformations is caused by the very transition to the knowledge economy. As a result, state institutions encourage wider access of the public and decision making officials to reliable data about the main trends in the society (historical, cultural, socio-economic, psychological, etc). As it was said by José Manuel Barroso in 2012, "It's your future. Europe's recovery and future prosperity depend on our ability to innovate, to bring together research, innovation and education, and to turn new ideas into products, services, jobs and well being for our citizens".

\section{DISCUSSION}

The development of a knowledge transfer program for DH is becoming an urgent task. In our opinion, the following areas can be identified in this area:

- work with cultural heritage: digital art, new media, creation of digital libraries, archives, databases of cultural heritage and museum collections; - 3D modeling of cultural objects, digital reconstructions that require joint efforts of humanities and specialists in digital technologies;

- legal regulation in the development and application of new technologies, forensic technical expertise;

- collection and analysis of data, their visualization, modeling, design of databases on key topical issues of current socio-economic, political and cultural processes, including digital ways of visualizing spatial-temporal data;

- e-learning and electronic information and educational environments in higher education;

- textology and linguistics in the digital age;
- new forms of accumulation and transfer of knowledge, organization of the academic community, educational environment, development and implementation of new digital tools, methods and models in the scientific and educational space, including the development of online resources, services and platforms, digital infrastructures, etc.;

- study of the features of the new era, Highhume / high humanitarian technologies, sociocultural consequences of digital technologies, critical analysis of their capabilities and limitations (multimedia systems and technologies, digital media, cyberculture, cyber psychology, the impact of digital technologies on people, interaction with artificial intelligence, intellectual systems and human intelligence, machine learning) [27]. In this context «Digital Humanities» are closely connected with informatics in humanities, which does not just apply the methods of informatics in humanitarian studies, but studies the laws of emergence and development of information in society, the philosophy and methodology of the information society, computerization as a social phenomenon.

In order to reveal the commercial potential of digital humanities, it is necessary to identify the main directions for knowledge exchange (contractual research, advanced professional education programs, etc.); to identify target sectors (business, society, social sphere) and geographical priorities (international, national, regional, local); to analyze priorities in cooperation with certain types of organizations, the main sources of funding, as well as the main mechanisms for monitoring and evaluating the development of knowledge transfer, including the assessment of economic and social effects.

Key to the implementation and effectiveness of knowledge transfer is the institutional background. The latter implies the restructuring or creation of organizational infrastructure, an example of which can be the knowledge transfer departments that have appeared in many universities recently. They perform the role of a "clipboard" between external customers and departments of the scientific and educational institution, its lecturers and researchers. Professionals involved in the organization of knowledge transfer should have the skills to communicate with representatives of the academic environment (researchers and lecturers of the university), and the ability to interact effectively with enterprises and organizations, i.e. the ability to speak the "language of business".

The motivation of the institution's employees to commercialize the research results and educational practices in the framework of the "knowledge transfer culture" also plays an important role.

The digital format of humanitarian knowledge significantly simplifies cooperation through the combination of information and communication technologies and related technological tools. In the conditions of the global environment for intercultural and interdisciplinary communication, integration into the international scientific and economic community is greatly facilitated. Thanks to information and communication technologies, the space barriers (distances, territories, borders) and time (time zones and work schedules) become blurred, which significantly expands the boundaries of the scientific sphere and the capabilities of the educational environment. 
Through the use of new technologies, there is an increase in the coverage of the scientific and educational field, which implies simultaneous access to many sources of scientific and educational information (electronic libraries, data banks, knowledge bases, scientific publications, etc.), to a wide range of specialists and researchers, as well as to a large number of students. Thus, in the field of education, on the agenda is a virtual university, in which most educational and scientific processes take place online. Today, electronic information and educational environment allows you to create a mobile and extensive system of advanced training and retraining, which will ensure that the level of graduates meets the current demands of the market. These provisions are also applicable to the field of humanities and humanitarian education.

\section{CONCLUSIONS}

In conclusion, it should be noted that the extent of the digital component in humanitarian knowledge will only increase due to interrelation with the so-called critical technologies. It is the technological parameters that determine the format of knowledge about a man and society, which closely corresponds to the current socio-economic and technological transformations and makes the demand for the emerging market of scientific and educational services. The development of knowledge transfer related to digital humanities becomes one of the most important tasks in the conditions of closer interaction of science and education with businesses, with the lack of support from the state and noticeable cuts in funding the humanities.

Ultimately, the cost-effective exchange of knowledge in the field of digital humanities implies a problem-oriented scientific analysis, which is vital for the current state of Russian scientific and educational space. It is necessary to update not only the theoretical aspects of the role and place of digital humanities in the digital age, but also to address the challenges of the fourth industrial revolution, the commercial viability of research and educational programs, etc. Methodical work in this direction is vital now, and this work can only be done by the researchers in the field of digital humanities.

It is an urgent task today to change the tradition of knowledge transfer design only in the context of nature and technical sciences, to overcome the backlog of digital infrastructure in social and humanitarian knowledge and skepticism regarding the possibility of commercializing the results of humanitarian research. Today, information and computer technologies provide support to researchers in the field of humanities and help them to master the new instrumental base and information environment. At the same time, researchers in the field of humanities can make the significant contribution to the development of new technologies and the implementation of modern mechanisms for the transfer of generated knowledge, thus contributing to innovative development in the digital age.

\section{REFERENCES}

[1] L. Argote, and P. Ingram, "Knowledge transfer: A basis for competitive advantage in firms," Organization-al behavior and human decision processes, Vol. 82, No. 1, pp. 150-169, 2000.
[2] J. Bresman, and J. Birkinshaw, "Nobel R. Knowledge transfer in international acquisitions," Journal of In-ternational Business Studies, № 30 (3), pp. 439-462, 1999.

[3] G. P. Huber, "Transfer of knowledge in knowledge management systems: unexplored issues and suggested studies," European Journal of Information Systems, № 10, pp. 72-79, 2001.

[4] A. O. Grudzinsky and A. B. Bedny, "Transfer of knowledge function of innovative University," Higher education in Russia, № 9, pp. 66-71, 2009

[5] J. Salmi, The Challenge of Establishing World-Class Universities, Directions in Development, Washington: World bank, cop., 2009.

[6] D. S. Siegel, D. Waldman, L. E. Atwater, and A. N. Link "Commercial knowledge transfers from universities to firms: improving the effectiveness of university-industry collaboration," Journal of High Technology Management Research, № 14, pp. 111133, 2003.

[7] D. C.Mowery, and B. N. Sampat, "Universities in National Systems," The Oxford Handbook of Innovation, J. Fagerberg, D. Mowery, R. Nelson, Eds. Oxford: Oxford University Press, 2005, pp. 209-239.

[8] S. Hagen "From Tech Transfer to knowledge exchange: European Universities in the Marketplace," Wen-ner-Gren International Series, Vol. 84, The University in the Market, London: Portland Press Ltd, 2008, pp. 103-117.

[9] K. R. Amanchaeva, "transfer of knowledge and technology - modern interpretation of concepts," Applied and theoretical studies: Collection of articles II international. scientific and practical. confer. June 2, 2018, Samara, Samara: ZNIC, 2018. pp. 34-37.

[10] M. Dacos, Manifesto for the Digital Humanities, Date Views 25.06.2019 http://tcp.hypotheses.org/501.

[11] S. M. Popova, "Analysis of domestic and foreign experience in the development of digital infrastructure of social and humanitarian studies," Genesis: historical studies, № 1, pp. 208 - 251, 2015.

[12] A. Yu. Volodin, "Digital Humanities 12 years later," Historical Informatics. Inform. technology and matemat. methods in historian. research and education, № 4, pp. 75-78, 2014.

[13] N. K. Hayles, How We Think: Digital Media and Contemporary Technogenesis. Chicago: University of Chicago Press, 2012.

[14] G. V. Mozhaeva, P. N. Mozhaeva-Reniya, V. A. Serbin, "Digital Humanities: organizational forms and research infrastructure," Bulletin of Thom. state University, No. 389, pp. 73-81, 2014.

[15] Vinogradova, E.Yu., Andreeva, S.L., Babkin, A.V., Galimova, A.I. Corporate information system - Element of efficient human resources management of the industrial-economic complex (2017) 2018January, pp. 63-66.

[16] I. Gregory, "Challenges and opportunities for digital history," Frontiers in Digit. Humanit, № 1. pp. 1-20, 2014.

[17] C. D'Ignazio, and R. Bhargava, "Creative Data Literacy: A Constructionist Approach to Teaching Infor-mation Visualization," Digital Humanities Quarterly, Vol. 12, № 4, 2018. Date Views 19.06.2019 http://www.digitalhumanities.org/dhq/vol/12/4/000403/000403.html.

[18] K. Glinka, C. Pietsch, and M. Dörk, "Past Visions and Reconciling Views: Visualizing Time, Texture and Themes in Cultural Collections," Digital Humanities Quarterly, Vol. 11, № 2, 2017. Date Views 19.06.2019 http://www.digitalhumanities.org/dhq/vol/11/2/000290/000290.html.

[19] A. Yu. Volodin, "Digital Humanities (digital Humanities): in search of self-determination," Bulletin of Perm University, history Series, №3 (26), pp. 5-12, 2014.

[20] L. I. Borodkin, "Virtual reconstruction of monastic complexes in Moscow: projects in the context of Digital Humanities," Bulletin of Perm University, History series, Vol. 3(26), pp. 107-112, 2014.

[21] Mapping the medieval city: space, place and identity in Chester c. 1200-1600, ed. by Catherine A. M. Clarke, Cardiff : Univ. of Wales press, 2011.

[22] I. V. Aladyshkin and S. B. Ulyanova, "Digital University - digital history: New approaches to the study of the history of St. Petersburg technical University," History of Polytechnic education in Russia: Proceedings of the all-Russian scientific and educational conference with international. participation, February 28, 2019 St. Petersburg. SPb.: POLYTECHNIC PRESS, 2019, ss. 84-91. 
[23] A New Companion to Digital Humanities, S. Schreibman, R. Siemens, and J. Unsworth, Eds. Chichester: Wiley Blackwell, 2016.

[24] D. Bylieva, V. Lobatyuk, N. Nikiforova, and M. Petrova "The Problem of "Sign Field" Creation for the Russian National Technology Initiative," 4th International Multidisciplinary Scientific Conference on Social Sciences and Arts SGEM2017, Book 6, Vol. 1, pp. 117-124, 2017.

[25] A. Kozlov, A. Kankovskaya, and A. Teslya, "The investigation of the problems of the digital compe-tences formation for Industry 4.0," workforce 2019 IOP Conference Series: Materials Science and Engineering 497 (1), 012011.
[26] M. V. Tlostanova, "Contours of the University of the XXI century in the context of the crisis of modernity," Higher education in Russia, № 1, pp. 24-36, 2013.

[27] O. D. Shipunova, I. P. Berezovskaya, L. M. Mureyko, V. V. Evseev, and L. I. Evseeva, "Personal intellec-tual potential in the e-culture conditions," Education, Vol. 39, № 40, P. 15, 2018. 